\title{
Article
}

\section{Fire safety aspects of PCM-enhanced gypsum plasterboards: An experimental and numerical investigation}

Asimakopoulou, Eleni, Kolaitis, Dionysios and Founti, Maria

Available at http://clok.uclan.ac.uk/31938/

Asimakopoulou, Eleni ORCID: 0000-0001-5644-1372, Kolaitis, Dionysios and Founti, Maria (2015) Fire safety aspects of PCM-enhanced gypsum plasterboards: An experimental and numerical investigation. Fire Safety Journal, 72 . pp. 50-58. ISSN 0379-7112

It is advisable to refer to the publisher's version if you intend to cite from the work. http://dx.doi.org/10.1016/j.firesaf.2015.02.004

For more information about UCLan's research in this area go to http://www.uclan.ac.uk/researchgroups/ and search for <name of research Group>.

For information about Research generally at UCLan please go to http://www.uclan.ac.uk/research/

All outputs in CLoK are protected by Intellectual Property Rights law, including Copyright law. Copyright, IPR and Moral Rights for the works on this site are retained by the individual authors and/or other copyright owners. Terms and conditions for use of this material are defined in the policies page.

\section{CLoK}

Central Lancashire online Knowledge www.clok.uclan.ac.uk

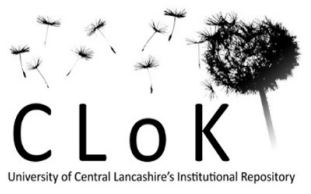


Fire safety aspects of PCM-enhanced gypsum plasterboards: An experimental and numerical investigation

\author{
Eleni K. Asimakopoulou, Dionysios I. Kolaitis* and Maria A. Founti
}

Laboratory of Heterogeneous Mixtures and Combustion Systems,

School of Mechanical Engineering, National Technical University of Athens

Heroon Polytechneiou 9, Polytechneioupoli Zografou, Athens 15780, Greece

*Corresponding author: e-mail: dkol@ central.ntua.gr, Tel.: +30-210-7724002, Fax: +30-210-7723527 


\begin{abstract}
New trends in building energy efficiency include thermal storage in building elements that can be achieved via the incorporation of Phase Change Materials (PCM). Gypsum plasterboards enhanced with micro-encapsulated paraffin-based PCM have recently become commercially available. This work aims to shed light on the fire safety aspects of using such innovative building materials, by means of an extensive experimental and numerical simulation study. The main thermo-physical properties and the fire behaviour of PCMenhanced plasterboards are investigated, using a variety of methods (i.e. thermo-gravimetric analysis, differential scanning calorimetry, cone calorimeter, scanning electron microscopy). It is demonstrated that in the high temperature environment developing during a fire, the PCM paraffins evaporate and escape through the failed encapsulation shell and the gypsum plasterboard's porous structure, emerging in the fire region, where they ignite increasing the effective fire load. The experimental data are used to develop a numerical model that accurately describes the fire behaviour of PCM-enhanced gypsum plasterboards. The model is implemented in a Computational Fluid Dynamics (CFD) code and is validated against cone calorimeter test results. CFD simulations are used to demonstrate that the use of paraffinbased PCM-enhanced construction materials may, in case the micro-encapsulation shells fail, adversely affect the fire safety characteristics of a building.
\end{abstract}

Keywords: Gypsum plasterboard, Phase Change Material, PCM, Fire Safety, CFD, TGA, DSC, Cone calorimeter, SEM

\title{
1. Introduction
}

The materials used in a building envelope can significantly affect the characteristics of a developing fire. Investigation of the thermal behaviour of construction materials in high temperatures is essential, due to their potential impact on the overall fire safety of a building.

Incorporation of Phase Change Materials (PCM) into construction materials has been proposed as a passive means of decreasing the overall heating and cooling demand of a building [1-3]. The high latent heat of PCM increases the overall thermal mass of building elements, resulting in lower diurnal indoor temperature fluctuations and reduced heat losses to the ambient [4]. PCM can be incorporated in a variety of construction materials, such as gypsum plasterboards, concrete or plaster [1,2]. Gypsum plasterboards, commonly used in lightweight construction as internal and external wall systems, have proven to be especially 
suitable for this purpose [5, 6]. Gypsum plasterboards (GP) incorporating paraffin-based PCM blends have become commercially available in the last decade. However, large-scale tests using GP enhanced with paraffin-based PCM have indicated that they fail to meet existing building safety requirements for room lining materials and their fire safety behaviour is worse compared to "plain" GP [7].

The current study, motivated by the increasing use of such innovative materials and the scarcity of literature reports focusing on their fire behaviour, evaluates the impact of PCMenhanced GP wall assemblies on the building's fire safety characteristics. Several test devices and experimental methods are used to determine the main thermo-physical properties of PCM-enhanced GP, as well as their thermal behaviour in a high temperature environment. Furthermore, a dedicated numerical model is developed to effectively describe the fire behaviour of PCM-enhanced construction materials; the model is implemented in a Computational Fluid Dynamics (CFD) code and, after being validated, is used to estimate the potential adverse effects in the context of building fire safety.

\subsection{Fire behaviour of gypsum plasterboards}

Gypsum plasterboards are widely used in the building industry as an easy to apply and mechanically enduring facing material for walls, floors and ceilings. In terms of building fire safety, GP are capable of decelerating the heat penetration through the wall assembly due to the gypsum "dehydration" process. When a GP is subjected to a high temperature environment, water molecules bound in its crystal lattice are released and transferred through the board, absorbing thermal energy and reducing the mean wall temperature. This highly endothermic process is known to improve the fire resistance of the wall assembly, thus enhancing the fire safety margins by allowing longer evacuation times [8].

A typical GP consists mainly of a calcium sulphate di-hydrate $\left(\mathrm{CaSO}_{4} 2 \mathrm{H}_{2} \mathrm{O}\right)$ mixture, which contains $21 \%$ (by weight) chemically bound water, enclosed by two sheets of surface covering paper. When calcium sulphate di-hydrate is heated, the chemically bound water starts to dissociate from the crystal lattice and is released in the form of water vapour. This process, known as gypsum dehydration, occurs in the temperature region between $90^{\circ} \mathrm{C}$ and $250^{\circ} \mathrm{C}$, depending on the heating rate. The dissociation of the chemically bound water takes place in two stages. In the first stage (Equation 1), the calcium sulphate di-hydrate loses $75 \%$ of its water, thus forming calcium sulphate hemi-hydrate $\left(\mathrm{CaSO}_{4} \cdot 1 / 2 \mathrm{H}_{2} \mathrm{O}\right)$. Further heating results in the onset of a second reaction (Equation 2), where the calcium sulphate hemi- 
hydrate loses the remaining water to form calcium sulphate anhydrite $\left(\mathrm{CaSO}_{4}\right)$. Both reactions are highly endothermic [9].

$\mathrm{CaSO}_{4} \cdot 2 \mathrm{H}_{2} \mathrm{O}_{(\mathrm{s})} \rightarrow \mathrm{CaSO}_{4} \cdot 1 / 2 \mathrm{H}_{2} \mathrm{O}_{(\mathrm{s})}+{ }^{3} /{ }_{2} \mathrm{H}_{2} \mathrm{O}_{(\mathrm{g})}$

$\mathrm{CaSO}_{4} \cdot{ }_{1} / \mathrm{H}_{2} \mathrm{O}_{(\mathrm{s})} \rightarrow \mathrm{CaSO}_{4}(\mathrm{~s})+{ }^{1} /{ }_{2} \mathrm{H}_{2} \mathrm{O}_{(\mathrm{g})}$

Gypsum dehydration and water vapour diffusion phenomena have a strong impact on the thermal behaviour of GP exposed to fire conditions. Accurate modelling of these phenomena requires the detailed solution of the respective heat and mass transfer equations across the width of the GP [9]. However, in the context of CFD analysis of building fire safety, the cost of such detailed simulations is currently prohibitive; therefore, various alternative methodologies, using a number of simplifying assumptions, have been developed [10].

\subsection{Fire behaviour of paraffin-based Phase Change Materials}

Commercially available organic PCM for building applications comprise mainly paraffin blends since they exhibit a range of desirable characteristics, such as high latent heat, ability to control the phase change temperature, low cost, non-corrosive characteristics and chemical stability. However, paraffin-based PCM exhibit two main weaknesses, i.e. low thermal conductivity and increased flammability [11, 12]; the latter may compromise the fire safety characteristics of a building. A range of small- and medium-scale tests have shown that the incorporation of fire retardants in the PCM may result in observable improvements in the overall fire safety of these materials $[13,14]$.

PCM micro-encapsulation has proven to be an easy and cost-effective way for PCM incorporation into construction materials [15]. Alternative methods, such as direct incorporation, immersion and macro-encapsulation, have fallen into disuse due to leakage problems, material incompatibility, tendency for solidification at the edges and poor thermal conductivity [7]. In the case of the micro-encapsulation technique, the PCM is enclosed in sealed, spherical, thin polymer capsules, ranging in size from $1 \mu \mathrm{m}$ to $300 \mu \mathrm{m}$, which are able to maintain their shape and prevent leakage during the phase change process [16].

In commercially available PCM-enhanced construction materials, the solid-liquid phase change occurs in the temperature range typically found indoors $\left(20-26^{\circ} \mathrm{C}\right)$, aiming to improve 
thermal comfort and energy efficiency. However, in a fire event, construction materials may be exposed to substantially higher temperatures, that can easily reach $800^{\circ} \mathrm{C}$ [17]; under such conditions, there is high possibility of encapsulation failure, PCM leakage and release of PCM vapours to the fire compartment $[1,13]$. When exposed to a high temperature environment, paraffin-based PCM, commonly exhibiting boiling points below $350^{\circ} \mathrm{C}$, evaporate. If the PCM encapsulation polymer shell fails due to the intense heating conditions, the produced paraffin vapours will be released to the porous structure of the gypsum plasterboard and, through a mass diffusion process, will emerge in the fire compartment. In this case, paraffin vapours are expected to ignite, increasing the fire load and thus adversely affecting the building's fire safety characteristics [14].

\section{Experimental investigation}

Experiments are performed using samples of commercial "plain" gypsum plasterboards (GP) and PCM-enriched gypsum plasterboards (GP+PCM) of the same thickness.

Commercially available paraffin-based PCM contain a mixture of paraffins to achieve optimum thermal characteristics in the temperature region related to thermal comfort. The exact composition of the PCM paraffin blend used in the investigated GP+PCM boards was unavailable; therefore, a range of physical properties of the PCM blend is measured to estimate its high temperature behaviour and to assist development of a numerical model.

\subsection{Thermo-Gravimetric Analysis}

A series of Thermo-Gravimetric Analysis (TGA) tests is performed, using a Setaram TGA device operated under inert gas (He) conditions. The behaviour of both "plain" (GP) and "PCM-enhanced" (GP+PCM) gypsum plasterboards is comparatively assessed in the temperature range $20-600^{\circ} \mathrm{C}$, using three different heating rate levels $\left(5^{\circ} \mathrm{C} / \mathrm{min}, 50^{\circ} \mathrm{C} / \mathrm{min}\right.$ and $80^{\circ} \mathrm{C} / \mathrm{min}$ ). Aluminium crucibles with a pinhole lid are used to hold the $55 \mathrm{mg}$ samples; the He purge flow rate used is $50 \mathrm{ml} / \mathrm{min}$. Initially, both GP and GP+PCM samples exhibit a similar mass loss behaviour (Figure 1) that corresponds to the onset of gypsum dehydration reactions; in fact, the two distinct peaks that can be identified in the instantaneous mass loss rate curves (Figure 2) correspond to the two gypsum dehydration reactions (Equations 1 and 2). However, at temperatures higher than $200-250^{\circ} \mathrm{C}$, the behaviour of the GP+PCM sample is differentiated, suggesting the occurrence of two additional thermal events (c.f. Figure 2). 
The first event, occurring at $227-347^{\circ} \mathrm{C}$ depending on the heating rate, is attributed to the evaporation of the PCM blend. The second event, occurring at higher temperatures (280$450^{\circ} \mathrm{C}$ ), is associated with the melting of the micro-encapsulation polymer shell [18, 19]. As expected, increasing the heating rate results in a "shift" of the temperature where the various thermal events are observed towards higher values; this behaviour is well established and is mainly attributed to the thermal inertia of the sample [Wendlandt, Brown]. Total mass measurements (Figure 1) suggest that approximately $18 \%$ of the GP+PCM sample mass is lost during the gypsum dehydration process, $12 \%$ is lost due to paraffin evaporation and $5 \%$ due to the polymer shell decomposition.

\subsection{Differential Scanning Calorimetry}

Differential Scanning Calorimetry (DSC) is used to estimate the approximate chemical composition of the PCM paraffin in a $14.11 \mathrm{mg}$ GP+PCM sample, using a nitrogen $\left(\mathrm{N}_{2}\right)$ purged DSC-1 Mettler Toledo calorimeter. A constant heating rate of $2^{\circ} \mathrm{C} / \mathrm{min}$ is used in this case to investigate the sample's behaviour in the $20-600^{\circ} \mathrm{C}$ temperature range; the $\mathrm{N}_{2}$ purge flow rate used is $200 \mathrm{ml} / \mathrm{min}$. The DSC test allows an accurate determination of the temperature range where PCM melting and evaporation is observed; the measured values for the onset, peak and endset temperatures for the melting and boiling processes, as well as the latent heat of evaporation, determined using standard techniques [20], are shown in Table 1. In order to define a single-species "surrogate" of the actual paraffin PCM blend used in the investigated GP+PCM sample, the measured values are compared to the respective physical properties of normal alkanes [21]. Hexadecane $\left(\mathrm{C}_{16} \mathrm{H}_{34}\right)$ is selected as the alkane exhibiting the best agreement; its relevant physical properties are also presented in Table 1.

\subsection{Cone Calorimeter Tests}

An FTT Cone Calorimeter (CC) is used to comparatively assess the fire behaviour of GP and GP+PCM samples. Overall, 3 tests are performed, following the general guidelines of the ISO 5660 standard [22]. A $50 \mathrm{~kW} / \mathrm{m}^{2}$ heat flux level is used for both materials (GP-50, $\mathrm{GP}+\mathrm{PCM}-50$ ); an additional GP+PCM sample is also tested at the $75 \mathrm{~kW} / \mathrm{m}^{2}$ heat flux level (GP+PCM-75), which is more representative of a typical fully-developed fire [23]. The 100 $\mathrm{mm} \times 100 \mathrm{~mm}, 12.5 \mathrm{~mm}$ thick, samples are mounted horizontally in the CC apparatus; their non-exposed (side and bottom) surfaces are insulated and externally wrapped with aluminium 
foil. All samples were preconditioned for a week in a controlled environment chamber $\left(23^{\circ} \mathrm{C}\right.$, $50 \%$ relative humidity). A type $\mathrm{K}$ thermocouple is placed at the bottom surface of each sample to monitor the temperature evolution at its unexposed side. A flow rate of $24 \mathrm{l} / \mathrm{s}$ is used in the gas extraction system. The estimated average error is $0.1 \%$ for the total mass measurements and 5\% for the heat release rate measurements [Zhao \& Dembsey].

Figure 3 (top) depicts the time evolution of the measured Heat Release Rate (HRR) for the three test cases considered. Identification of the underlying physical phenomena corresponding to each HRR peak observed is made by combining information obtained in the TGA and DSC measurements, CFD simulations and relevant literature reports. Immediately after the test initiation, a sharp peak in HRR is observed in the GP case, which is attributed to the prompt burning of the surface covering paper [7, 24]. After the initial peak, HRR values in the GP sample decrease to practically negligible levels. However, the GP+PCM samples exhibit a sustained heat release activity period due to PCM evaporation and subsequent PCM vapour combustion. Two major HRR peaks are observed in both GP+PCM tests; the first peak is attributed to the prompt evaporation and subsequent combustion of the PCM that lies near the exposed surface. The second HRR peak, observed 1000 - $1200 \mathrm{~s}$ after the test initiation, corresponds to the diffusion-controlled release and combustion of the PCM vapours, as a result of the gradual thermal failure of the micro-encapsulation polymer shells. In addition, total mass measurements (Figure 3, bottom) suggest that the GP+PCM samples result in higher total mass loss and mass loss rates compared to the plain GP sample; evidently, the additional mass that is lost corresponds to the evaporating PCM and the failing polymer encapsulation shells.

The main CC results are presented in Table 2. The mass loss observed in the GP sample is owed solely to the water vapour release due to gypsum dehydration (Equations 1 and 2), whereas the measured heat release is attributed to the combustion of the surface covering paper. The GP+PCM samples exhibit significantly higher total mass loss, total heat release and peak HRR values compared to the respective GP sample, due to PCM evaporation and subsequent PCM vapour combustion. As expected, higher peak HRR values and shorter ignition times are observed when the level of incident heat flux increases $\left(75 \mathrm{~kW} / \mathrm{m}^{2}\right)$; however, the total mass loss and the total heat released are comparable for both heat flux levels. When the heat flux is increased, the time to peak HRR and the time to ignition are shorter, whereas the observed peak HRR value is increased; this behaviour demonstrates the importance of prompt PCM evaporation phenomena during the early stages of the test.

Photographs of the exposed surface taken after the CC test suggest that the plain GP 
sample shows minimal external damage (Figure 4, left); the surface covering paper is partially burnt and no significant cracking is observed. On the contrary, the GP+PCM sample exhibits external and internal cracking and increased brittleness (Figure 4, right), suggesting a significant reduction in its mechanical strength.

\subsection{Scanning Electron Microscopy}

The micro-structure of the GP+PCM material is examined in a Jeol JSM-5600 Scanning Electron Microscope (SEM), equipped with an X-ray EDS (Energy Dispersive Spectroscopy) micro-probe. A GP+PCM sample is examined in the SEM before and after the $75 \mathrm{~kW} / \mathrm{m}^{2}$ cone calorimeter test. The sample is covered with gold and is observed at $20 \mathrm{keV}$ for a period of $60 \mathrm{~s}$. SEM images of the PCM-enriched GP before being exposed to an intense heat flux reveal the porous structure of the GP (Figure 5, top left). The spherical polymer capsules containing the PCM are clearly depicted (Figure 5, bottom left); the average capsule diameter in the examined sample is found to be in the order of $5 \mu \mathrm{m}$. Significant changes are observed in the microstructure of the GP+PCM sample after being exposed to a $75 \mathrm{~kW} / \mathrm{m}^{2}$ heat flux (Figure 5, right). The majority of the PCM-enclosing spherical capsules are destroyed, thus corroborating the assumption that the produced PCM vapours are released to the ambient. The porous structure of the GP is also affected; using the X-ray EDS method, it is revealed that the remaining crystals of the calcium sulphate anhydrite are surrounded by a homogeneous melted mixture of calcium, sulphur and silicon.

\section{Numerical simulations}

The increasing trend of developing and implementing "performance-based" fire safety codes necessitates the use of dedicated fire simulation tools, such as zone models or Computational Fluid Dynamics (CFD) codes; the latter, can be used in a wide field of applications related to building fire safety. Motivated by the need to effectively simulate the thermal behaviour of PCM-enriched construction materials exposed to fire, a dedicated numerical model is developed, appropriate for implementation in fire simulation CFD codes. The model development is based on the information obtained from the experimental campaign described in Section 2. The model is implemented in a CFD code and is validated using measurements obtained in the cone calorimeter tests. In addition, numerical results are used to demonstrate the potential adverse effects of PCM on the fire safety characteristics of 
GP clad buildings.

The Fire Dynamic Simulator (FDS), version 6.1.2, is used to perform the CFD simulations. The FDS code, developed by NIST [25], is a CFD tool capable of simulating fundamental fire dynamics and combustion phenomena. A form of the Navier-Stokes equations, appropriate for low-speed, thermally driven flows, is numerically solved, using a three-dimensional, Cartesian grid. The fire behaviour of multi-layered wall assemblies can be simulated by using detailed thermo-physical properties (e.g. density, thermal conductivity, specific heat, surface emissivity) for each material. The FDS code has been extensively validated in a variety of fire-related flows [26]. Simulation of solid phase reactions (e.g. pyrolysis, dehydration) is performed utilizing the Arrhenius equation formulation. Equation (3) corresponds to the general form of the Arrhenius equation, used to determine the reaction rate $\left(r_{j}\right)$ of the $j$-th chemical reaction that involves the $i$-th solid species as a reactant. The required kinetic parameters are the pre-exponential factor $\left(A_{j}\right)$, the activation energy $\left(E_{j}\right)$ and the reaction order $\left(n_{j}\right)$. Selection of the proper kinetic parameters for solid reactions is very challenging; values derived from small- and large-scale experiments may exhibit differences of several orders of magnitude. In the FDS code, each solid component undergoing a chemical reaction may simultaneously yield user-defined quantities of solid residue $\left(v_{r e s}\right)$, water vapour $\left(v_{H 2 O}\right)$ and combustible gaseous fuel $\left(v_{\text {gas }}\right)$, expressed as mass yields.

$$
r_{j}=A_{j} Y_{s, i}^{n_{j}} \exp \left(-\frac{E_{j}}{R T}\right)
$$

\subsection{Model development}

The model focuses on effectively describing the PCM evaporation process, which leads to combustible PCM vapours emerging in the fire compartment. Surface cracking phenomena, appearing when a GP+PCM sample is exposed to a high heat flux (c.f. Figure 4), are neglected. Moreover, due to the lack of information regarding the physical and chemical properties of the polymer micro-encapsulation shell, pyrolysis reactions associated with the polymer shell disintegration process are neglected. When the temperature of the GP+PCM wall assembly exceeds the boiling point of the PCM, the produced PCM vapours are assumed to be immediately released into the GP porous structure. This assumption corresponds to a "worst case scenario", i.e. complete failure of all polymer encapsulation shells in high temperatures, which is, however, supported by the lack of intact spherical shells in the post- 
fire SEM images of the GP+PCM samples (c.f. Figure 5, right).

Aiming to limit the complexity of the developed model and the associated computational cost $[25,26]$, a single-species PCM is considered. Results obtained in the low heating rate DSC test (c.f. Section 2.2) are used to select hexadecane $\left(\mathrm{C}_{16} \mathrm{H}_{34}\right)$ as the closest single-species surrogate of the actual paraffin PCM blend used in the GP+PCM sample. The thermophysical properties of the resultant combustible PCM vapours, e.g. lower heating value $(43950 \mathrm{~kJ} / \mathrm{kg})$, are considered to be identical to that of gaseous hexadecane [21]. The hexadecane evaporation process is implemented in the FDS code using a first-order chemical reaction approximation (Equation 4).

$\mathrm{C}_{16} \mathrm{H}_{34}(\mathrm{l}) \rightarrow \mathrm{C}_{16} \mathrm{H}_{34}(\mathrm{~g})$

The proposed GP+PCM model is essentially an extension of a recently developed gypsum dehydration solid reaction kinetics model [10]. The original GP model [10] uses the Arrhenius equation formulation to simulate the two gypsum dehydration reactions (Equations 1 and 2); the relevant kinetic parameters, estimated by TGA test results, are shown in Table

3. Combustion of the surface covering paper is neglected. In addition, temperature-dependent physical properties are used to effectively describe the thermal behaviour of GP [10]. The original GP model has been implemented in the FDS code and has been validated against available temperature measurements obtained in a GP assembly tested in a small-scale fire resistance furnace [10].

The proposed GP+PCM model comprises the original gypsum dehydration model plus the additional PCM evaporation "reaction" (Equation 4). Aiming to increase the accuracy of the developed model and also to facilitate its implementation in CFD codes, where the Arrhenius reaction assumption is commonly used for solid phase reactions, a "kinetic" modelling approach is used to describe paraffin evaporation, which is essentially a "physical" and not "chemical" process. The kinetic parameters for PCM evaporation are determined using the TGA measurements obtained at three different heating rate levels (c.f. Section 2.1) by employing the model-free integral iso-conversional Kissinger-Akahira-Sunose (KAS) methodology [Vyazovkin et al. 2011]. A first order reaction is assumed based on the KAS analysis; values of the estimated kinetic parameters are given in Table 3.

The developed GP+PCM model uses Equations (1) and (2) to quantify water vapour release due to gypsum dehydration reactions and Equation (4) to quantify the release of 
combustible hexadecane vapours due to PCM evaporation. When the predicted temperature of the GP+PCM wall assembly exceeds the boiling point of PCM, hexadecane vapours are assumed to be released, through the GP porous structure, to the adjacent fire compartment. The produced vapours can be subsequently ignited and burnt, increasing the effective fire load of the compartment. Dispersion of the released water vapour and combustible PCM vapours in the fire compartment is simulated by solving the corresponding species conservation equations in the CFD code; gaseous combustion of the produced PCM vapours is modelled using a mixture fraction model.

The model is appropriate for simulation of both GP and GP+PCM wall assemblies. When a "plain" GP is considered, only Equations (1) and (2) are activated; the initial material composition is assumed to be $100 \% \mathrm{CaSO}_{4} \cdot 2 \mathrm{H}_{2} \mathrm{O}$. On the other hand, when a GP+PCM wall assembly is simulated, Equations (1), (2) and (4) are taken into account; in this case, the initial composition is assumed to be $88 \% \mathrm{CaSO}_{4} \cdot 2 \mathrm{H}_{2} \mathrm{O}$ and $12 \%$ hexadecane (PCM) (c.f. Section 2.1).

\subsection{Validation Study}

The developed GP+PCM model is validated by performing both 1D and 3D CFD simulations of the cone calorimeter tests presented in Section 2.3. The 1D simulations are essentially condensed-phase simulations, where only the solid-phase heat transfer solver of the FDS code is used. The computational domain, measuring $100 \mathrm{~mm} \times 100 \mathrm{~mm} \times 12.5 \mathrm{~mm}$, corresponds to the actual dimensions of the CC test sample; four separate test cases, pertaining to different sample material (GP, GP+PCM) and heat flux levels $\left(50 \mathrm{~kW} / \mathrm{m}^{2}, 75\right.$ $\mathrm{kW} / \mathrm{m}^{2}$ ) are considered. Adiabatic boundary conditions are used on all sides of the sample, expect from its top surface, where a constant net radiative heat flux value is prescribed. The initial mass fraction of PCM is assumed to be $12 \%$.

Aiming to demonstrate the applicability of the developed GP+PCM model in the context of CFD fire simulations, a series of additional 3D CFD simulations is also performed. In the majority of CFD simulations of CC tests for both charring [28,29] and non-charring materials [30-32], participation of the gas phase in radiative heat transfer is neglected [2830]. In order to eliminate errors associated with the use of this simplifying assumption, a detailed simulation approach is followed by taking into account gas phase radiation phenomena between the cone heater and the material surface. The simulation domain closely reproduces the actual geometric configuration of the $\mathrm{CC}$ test [22]. The outer dimensions of 
the simulation domain, encompassing both the cone and the sample, are $200 \mathrm{~mm} \times 200 \mathrm{~mm} \times$ $225 \mathrm{~mm}$. The computational grid consists of 576,000 cubic $(2.5 \mathrm{~mm}$ side $)$ cells.

The interior side of the cone heater is maintained at a uniform constant temperature, carefully calibrated to yield the required (i.e. $50 \mathrm{~kW} / \mathrm{m}^{2}$ or $75 \mathrm{~kW} / \mathrm{m}^{2}$ ) value of incident heat flux at the centre of the sample. The unexposed sides of the sample are considered to be adiabatic, approximating the thermal insulation used in the $\mathrm{CC}$ tests. The external boundaries of the simulation domain are open to the ambient, except from the top boundary that is assigned a constant 2.4 1/s gas outflow, corresponding to the actual flow rate measured in the gas extraction system during the $\mathrm{CC}$ test. The emissivity of the GP+PCM exposed surface is assumed to be 0.9 [8]. The absorption coefficients of the gas mixture are computed using the RADCAL narrow-band model [25]. A total computational time of $900 \mathrm{~s}$ is used; the minimum numerical time-step, which is dynamically adjusted by the FDS code, is $1.68 \mathrm{~ms}$.

In Figure 6, 1D and 3D simulation results for the time evolution of the unexposed bottom surface temperature are compared to measurements obtained in the two CC tests $\left(50 \mathrm{~kW} / \mathrm{m}^{2}\right.$ and $75 \mathrm{~kW} / \mathrm{m}^{2}$ ). Good qualitative and quantitative agreement is achieved in both cases; predictions of the 3D simulations exhibit a slightly better agreement with the experimental data compared to the corresponding 1D simulations. A similar behaviour is observed in Figure 7, where predictions of the instantaneous total mass are compared to the measured values; once more, 3D simulations achieve better levels of agreement. In general, the discrepancies between predictions and experimental data are attributed to the employed modelling assumptions, especially in terms of the initial composition of the GP+PCM sample and the use of a single species PCM "surrogate". In predictions of the total mass of the sample the observed discrepancies are larger, since a range of mass-related phenomena, such as surface covering paper combustion and polymer capsule thermal degradation and disintegration, are not taken into account. Overall, the validation study confirms the ability of the developed model to effectively simulate the main physico-chemical phenomena, i.e. gypsum dehydration and PCM evaporation, associated with the thermal behaviour of $\mathrm{GP}+\mathrm{PCM}$ wall assemblies exposed to fire.

\subsection{CFD simulation results}

The potential adverse effect of PCM-enhanced construction materials in a typical compartment fire scenario is clearly illustrated in Figure 8, where gas temperature predictions immediately above the $\mathrm{CC}$ testing samples, exposed to a $50 \mathrm{~kW} / \mathrm{m}^{2}$ heat flux, are depicted for 
both the examined test cases (GP, GP+PCM). It is evident that the predicted gas temperatures are significantly higher in the GP+PCM case, due to the increased fire load owed to the produced PCM vapours (c.f. Figure 3). The developed model allows quantification of the temperature increase related to the use of PCM-enhanced construction materials, in an effort to enhance the accuracy of relevant CFD fire engineering design analyses.

A prominent feature of the developed model, when implemented in a CFD code, is its ability to provide quantitative information pertaining to the PCM paraffin vapour production, dispersion and combustion processes, which would be otherwise impossible to obtain. In order to illustrate this capability, an additional CFD simulation of the GP+PCM cone calorimeter test is performed; in this case, the produced PCM vapours are assumed to be essentially a non-combustible "inert" gas, thus allowing monitoring its temporal and spatial dispersion rates. CFD predictions of the $\mathrm{C}_{16} \mathrm{H}_{34}$ vapour $1 \%$ mass fraction iso-surface, at various time steps, are shown in Figure 9; the vapours produced in the sample are released through its top side and are then mixed with the ambient air, resulting in the formation of a potentially combustible mixture. Significant quantities of $\mathrm{C}_{16} \mathrm{H}_{34}$ vapour are produced, even at the later stages of the test; however, it is reminded that these CFD simulations correspond to a "worst case scenario", where all micro-encapsulation shells are considered to fail and, therefore, the entire initial mass of PCM in the GP+PCM sample eventually evaporates.

\section{Concluding remarks}

This work has investigated the fire safety aspects of PCM-enhanced gypsum plasterboards and their potential adverse effect on the fire behaviour of a building, should the encapsulation shell fail. The differences in the fire performance of plain gypsum plasterboards and gypsum plasterboards enriched with PCM have been experimentally and numerically assessed.

Experiments have provided insight in the physical and chemical processes occurring under fire conditions and quantitative information on the physical properties of the PCM, required for model development. TGA tests have revealed the distinctive differentiation in the fire behaviour of the two materials. Significantly higher total mass loss and additional mass loss rate events have been observed in the GP+PCM sample. DSC measurements allowed estimation of important physical properties, i.e. melting point, boiling point, latent heat of evaporation; the latter have been used to determine that hexadecane can serve as a singlespecies modelling surrogate of the unknown PCM-blend used in the investigated commercial $\mathrm{GP}+\mathrm{PCM}$ sample. The $\mathrm{CC}$ tests have demonstrated the deterioration of the GP+PCM 
material's fire behaviour characteristics compared to a "plain" GP, by quantifying the additional HRR associated with paraffin vapour release and combustion. Finally, SEM photographs have revealed the complete failure of the encapsulation shells under fire conditions.

A dedicated numerical model has been developed accounting for the gypsum dehydration, PCM evaporation and combustion processes. The model has been implemented in a CFD code and has been validated against CC measurements; despite simplifying assumptions, it was found to accurately capture measured temperatures and mass loss rates. Both $1 \mathrm{D}$ and 3D simulations have been performed; the latter were found to exhibit better agreement with measurements compared to the former. 3D numerical results have been used to demonstrate the merits of the developed model in the context of CFD simulations; the temporal and spatial distribution of the evaporated PCM paraffins can be monitored, allowing quantification of the additional fire load imposed on the fire compartment. Further modelling work is planned, aiming to investigate the effect of important physical phenomena, such as mass transfer through the gypsum porous structure and failure modes of the polymer encapsulation shells.

Although the present study focuses on paraffin-based PCM incorporated in gypsum plasterboards, it is anticipated that paraffins will exhibit similar qualitative characteristics when incorporated in other construction materials (e.g. concrete). Therefore, results presented in this work are not only pertinent to the investigated material but have a wider scope, by proposing an analysis methodology which is relevant to any application of paraffin-based PCM in construction materials. The adverse impact of paraffin-based PCM may be reduced, or even eliminated, using a variety of methods, such as incorporation of flame retardants in the PCM blend or the GP core, shifting from organic to inorganic PCM, use of fire-resistant encapsulating coatings etc. These methodologies are beyond the scope of the present work, which nevertheless provides quantitative data for worst case scenarios that may assist product developers or act as guidelines for new products.

\section{Acknowledgements}

The work has been financially supported by the "Fire-Facts" project in the frame of the ARISTEIA action (operational programme "Education and Lifelong Learning") that is cofinanced by Greece and the E.U. and by the E.C. in the frame of the FP7 project "MeeFS: Multifunctional Energy Efficient Façade System for Building Retrofitting” (EeB.NMP.20113, Grant No. 285411). The assistance of Prof. M. Stamatakis and S. Kavouri (Faculty of 
Geology and Geo-Environment, National and Kapodistrian University of Athens, Greece), of Ass. Prof. T. Panidis and Dipl. Eng. V. Papadogianni (Department of Mechanical Engineering and Aeronautics, University of Patras, Greece) and of Prof. I. Paspaliaris, Dr. A. Peppas and Dipl. Eng. N. Athanasakou (School of Mining and Metallurgical Engineering, National Technical University of Athens, Greece) in performing the SEM, CC and TGA tests, respectively, is gratefully acknowledged.

\section{References}

[1]. L.F. Cabeza, A. Castell, C. Barreneche, A. de Gracia, A.I. Fernandez, Materials used as PCM in thermal energy storage in buildings: A review, Renew. Sus. Energ. Rev. 15 (2011) 1675-1695.

[2]. D. Zhou, C.Y. Zhao, Y. Tina, Review on thermal energy storage with phase change materials (PCMs) in building applications, Appl. Energ. 92 (2012) 593-605.

[3]. F. Agyenim, N. Hewitt, P. Eames, M. Smyth, A review of materials, heat transfer and phase change problem formulation for latent heat thermal energy storage systems (LHTESS), Renew. Sus. Energ. Rev. 14 (2010) 615-628.

[4]. C. Voelker, O. Kornadt, M. Ostry, Temperature reduction due to the application of phase change materials, Energ. Buildings 40 (2008) 937-944.

[5]. N. Soares, J.J. Costa, A.R. Gaspar, P. Santos, Review of passive PCM latent heat thermal energy storage systems towards buildings' energy efficiency, Energ. Buildings 59 (2013) 82-103.

[6]. N. Shulka, A. Fallahi, J. Kosny, Performance characterization of PCM impregnated gypsum board for building applications, Energy Procedia 30 (2012) 370-379.

[7]. D. Banu, D. Feldman, F. Haghighat, J. Paris, D. Hawes, Energy-storing wallboard: Flammability tests, J. Mater. Civil Eng. 10 (1998) 98-105.

[8]. C.Y. Wang, C.N. Ang, Effect of moisture transfer on specific heat of gypsum plasterboard at high temperatures, Constr. Build. Mater. 16 (2004) 505-515.

[9]. D.A. Kontogeorgos, M.A. Founti, Numerical investigation of simultaneous heat and mass transfer mechanisms occurring in a gypsumboard exposed to fire, Appl. Therm. Eng. 30 (2010) 1461-1469.

[10]. D.I. Kolaitis, M.A. Founti, Development of a solid reaction kinetics gypsum dehydration model appropriate for CFD simulation of gypsum plasterboard wall assemblies exposed to fire, Fire Safety J. 58 (2013) 151-159. 
[11]. V.V. Tyagi, S.C. Kaushik, S.K. Tyagi, T. Akiyama, Development of phase change materials based microencapsulated technology for buildings: A review, Renew. Sus. Energ. Rev. 15 (2011) 1373-1391.

[12]. A. Sharma, V.V. Tyagi, C.R. Chen, D. Buddhi, Review on thermal energy storage with phase change materials and applications, Renew. Sus. Energ. Rev. 13 (2009) 318345.

[13]. P. Sittisart, M.M. Farid, Fire retardants for phase change materials, Appl. Energ. 88 (2011) 3140-3145.

[14]. Y. Cai, Y. Hu, L. Song, Y. Tang, R. Yang, Y. Zhang, Z. Chen, W. Fan, Flammability and thermal properties of high density polyethylene/paraffin hybrid as a form-stable phase change material, J. Appl. Polym. Sci. 99 (2006) 1320-1327.

[15]. M. Hunger, A.G. Entrop, I. Mandilaras, H.J.H. Brouwers, M.A. Founti, The behavior of self-compacting concrete containing micro-encapsulated Phase Change Materials, Cement Concrete Comp. 3 (2009) 731-743.

[16]. M.N.A. Hawlader, M.S. Uddin, M.M. Khin, Microencapsulated PCM thermal-energy storage system, Appl. Energ. 74 (2003) 195-202.

[17]. W.D. Walton, P.H. Thomas, Estimating temperatures in compartment fires, SFPE Handbook of Fire Protection Engineering, $2^{\text {nd }}$ ed., National Fire Protection Association, Quincy, MA, 1995.

[18]. L. Sanchez-Silva, J.F. Rodriguez, A. Romero, A.M. Borreguero, M. Carmona, P. Sanchez, Microencapsulation of PCMs with a styrene-methyl methacrylate copolymer shell by suspension-like polymerisation, Chem. Eng. J. 157 (2010) 216-222.

[19]. H. Willax, B. Katz, M.R. Jung, S. Altmann, E. Jahns, Gypsum Wall Board Containing Micro-encapsulated Latent Heat Accumulator materials, Patent Number 20120196116 (2 August 2012).

[20]. B. Wundelich, Thermal Analysis, Academic Press Inc., UK, 1990.

[21]. C.L. Yaws, Handbook of Thermodynamic and Physical Properties of Chemical Compounds, Knovel, New York, 2003.

[22]. ISO 5660-1:1993; Fire tests - Reaction to fire heat release -Part 1: Rate of heat release from building products (cone calorimeter method), International Standards Organization, Geneva, Switzerland, 1993.

[23]. B. Schartel, T.R. Hull, Development of fire-retarded materials - Interpretation of cone calorimeter data, Fire Mater. 31 (2007) 327-354.

[24]. J.R. McGraw, F.W. Mowrer, Flammability and dehydration of painted gypsum 
wallboard subjected to fire heat fluxes, Fire Safety Sci. 6 (2000) 1003-1014.

[25]. K. McGrattan, S. Hostikka, J. Floyd, Fire Dynamics Simulator User's Guide, NIST Special Publication 1019-5, 2010.

[26]. K. McGrattan, S. Hostikka, J. Floyd, R. McDermott, Fire Dynamics Simulator (Version 5) Technical Reference Guide, Volume 3: Validation, NIST Special Publication 1018-5, 2010.

[27]. R.E. Lyon, An integral method of non-isothermal kinetic analysis, Thermochim. Acta 297 (1997) $117-124$.

[28]. R.K.K. Yuen, G.H. Yeoh, G. Vahl Davis, E. Leonardi, Modelling the pyrolysis of wet wood - II. Three-dimensional cone calorimeter simulation, Heat Mass Transfer 50 (2009) 4387-4399.

[29]. V. Novozhilov, B. Moghtaderi, D.F. Fletcher, J.H. Kent, Computational fluid dynamics modelling of wood combustion, Fire Safety J. 36 (1996) 69-84.

[30]. F. Kempel, B. Schartel, G.T. Linteris, S.I. Stoliarov, R.E. Lyon, R.N. Waltes, A. Hofman, Prediction of the mass loss rate of polymer materials: Impact of residue formation, Combust. Flame 159 (2012) 2974-2984.

[31]. D.M. Marquis, M. Pavageau, E. Guillaume, C. Chivas-Joly, Modelling decomposition and fire behaviour of small samples of a glass-reinforced polyester/balsa-cored sandwich material, Fire Mater. 37 (2012) 413-439.

[32]. Y.M. Ferng, C.H. Liu, Investigation of the burning characteristics of electric cables used in the nuclear power plant by way of 3-D transient FDS code, Nucl. Eng. Des. 241 (2011) 88-94.

[33]. International Standard ISO9705, Fire tests - Full-scale room test for surface products, Genève, Switzerland, 1993.

[34]. B. Merci, K.V. Maele, Numerical simulations of full-scale enclosure fires in a small compartment with natural roof ventilation, Fire Safety J. 43 (2008) 495-511.

[35]. C.H. Lin, Y.M. Ferng, W.S. Hsu, Investigating the effect of computational grid sizes on the predicted characteristics of thermal radiation for a fire, Appl. Therm. Eng. 29 (2009) 2243-2250.

[36]. S. Yuan, J. Zhang, Large eddy simulation of compartment fire with solid combustible, Fire Safety J. 44 (2009) 349-362.

[37]. X. Zhang, M. Yang, J. Wang, Y. He, Effects of computational domain on numerical simulation of building fires, J. Fire Prot. Eng. 20 (2010) 225-250.

[38]. L.S. Manzello, G.R. Gann, R.S. Kukuck, B.D. Lenhert, Influence of gypsum board 
type on real fire performance of partition assemblies, Fire Mater. 31 (2007) 425-442.

[39]. EN 1995-1-2, Eurocode 5, Design of timber structures - Part 1-2: General - Structural fire design, Brussels, Belgium, 2004.

[40]. Vyazovkin S., Burnham A.K., Criado J.M., Perez-Maqueda L.A., Popescu C., Sbirrazuoli N., "ICTAC Kinetics Committee recommendations for performing kinetic computations on thermal analysis data”, Thermochimica Acta, Vol. 520, pp. 1-19, 2011.

[41]. L. Zhao and N.A. Dembsey, "Measurement uncertainty analysis for calorimetry apparatuses" Fire and Materials, 32(1), pp.1-26, 2008.

[42]. W.W. Wendlandt, "Thermal Analysis", $3^{\text {rd }}$ Edition, John Willey and Sons, 1986.

[43]. B. M. E. Brown, "Introduction to Thermal Analysis: Techniques and Applications", $2^{\text {nd }}$ Edition, Kluwer Academic Publishers, 2001. 


\section{Figure Captions}

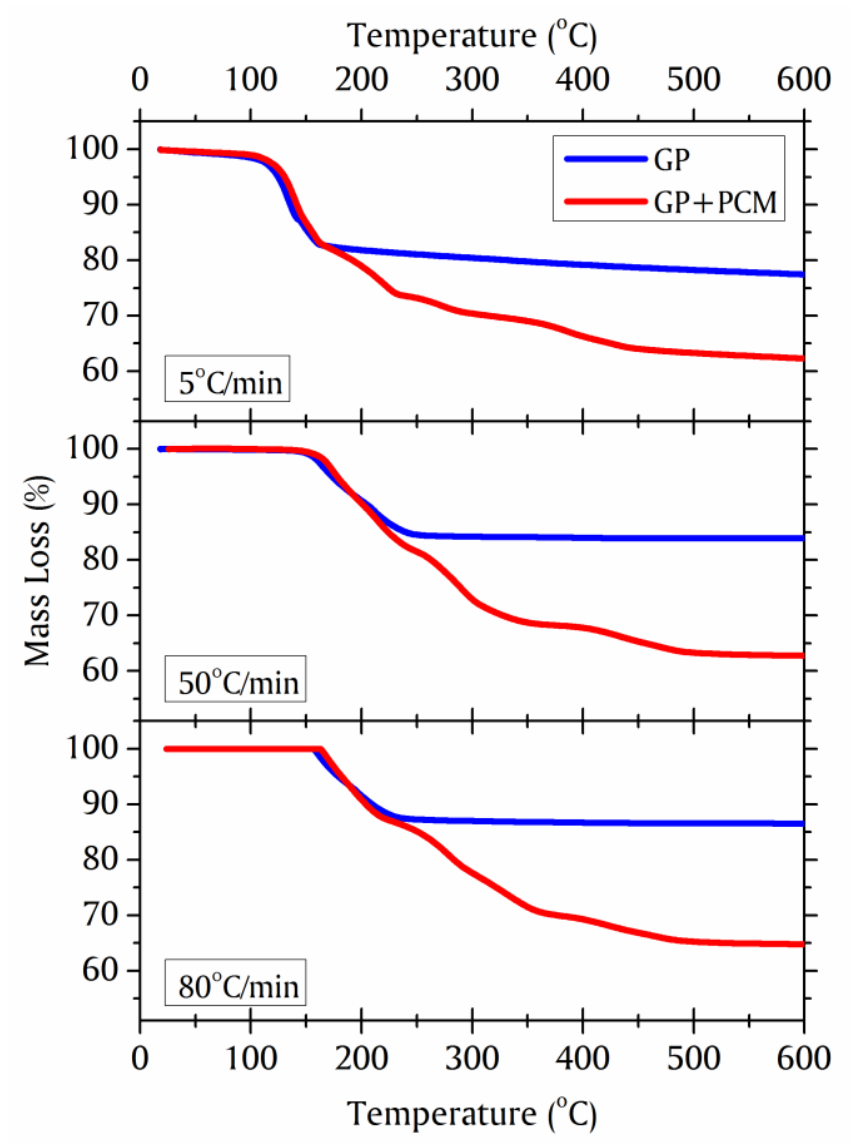

Figure 1. Time evolution of the total mass of GP and GP+PCM samples, using TGA heating rate levels of $5^{\circ} \mathrm{C} / \mathrm{min}$ (top), $50^{\circ} \mathrm{C} / \mathrm{min}$ (middle) and $80^{\circ} \mathrm{C} / \mathrm{min}$ (bottom). 


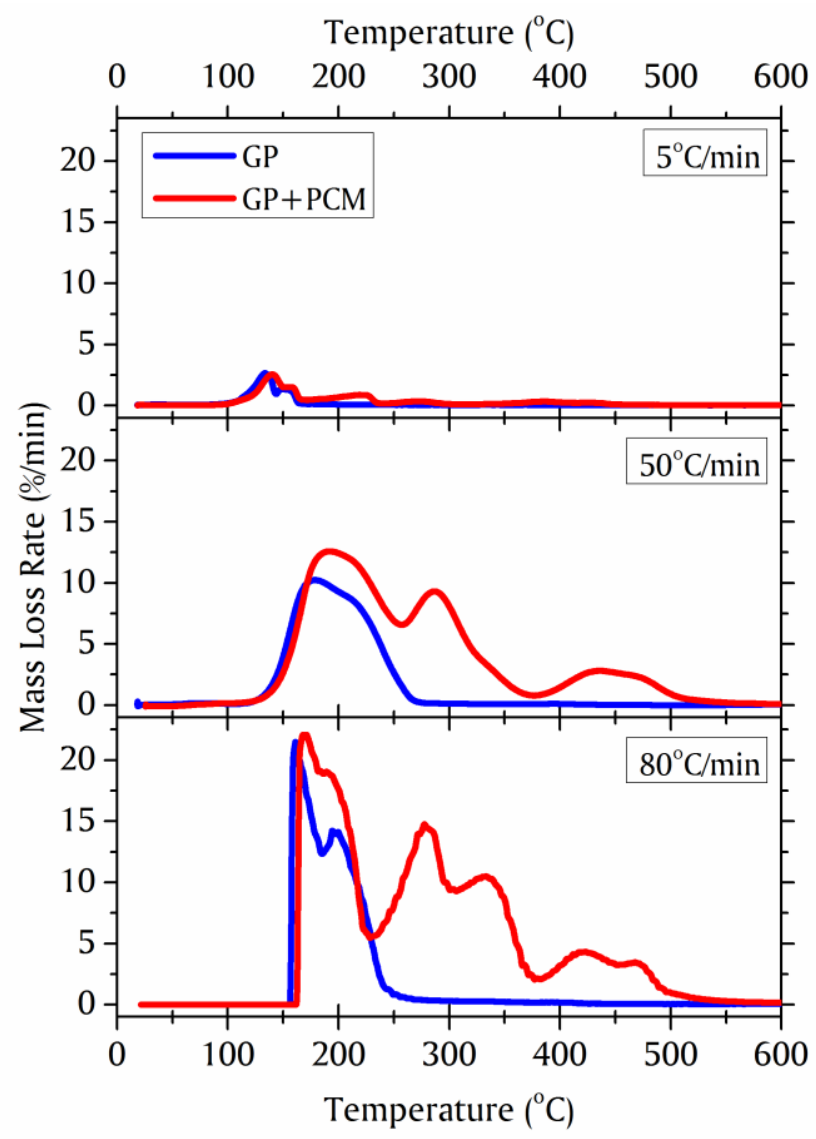

Figure 2. Time evolution of the mass loss rate of GP and GP+PCM samples, using TGA heating rate levels of $5^{\circ} \mathrm{C} / \mathrm{min}$ (top), $50^{\circ} \mathrm{C} / \mathrm{min}$ (middle) and $80^{\circ} \mathrm{C} / \mathrm{min}$ (bottom). 


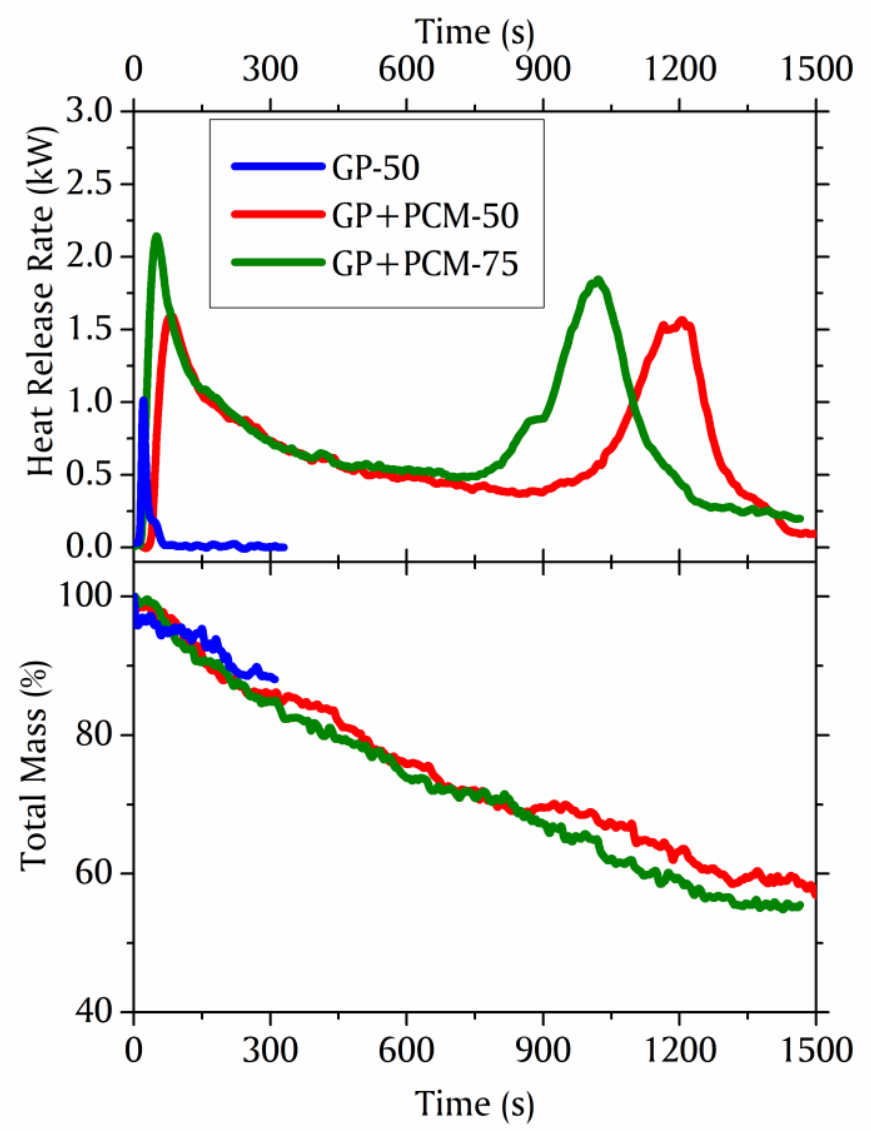

Figure 3. Time evolution of heat release rate (top) and total mass (bottom) of GP and GP+PCM samples, obtained in the cone calorimeter tests.

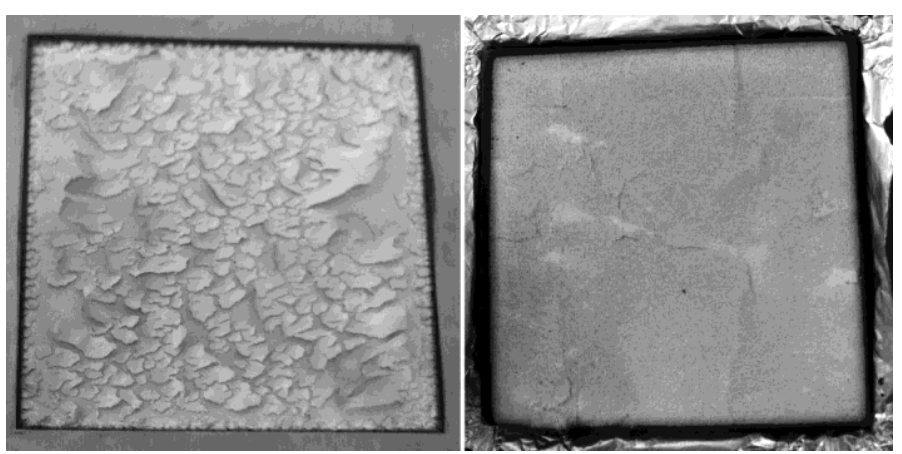

Figure 4. View of the exposed surface of the GP (left) and GP+PCM (right) samples, after the $50 \mathrm{~kW} / \mathrm{m}^{2}$ cone calorimeter test. 

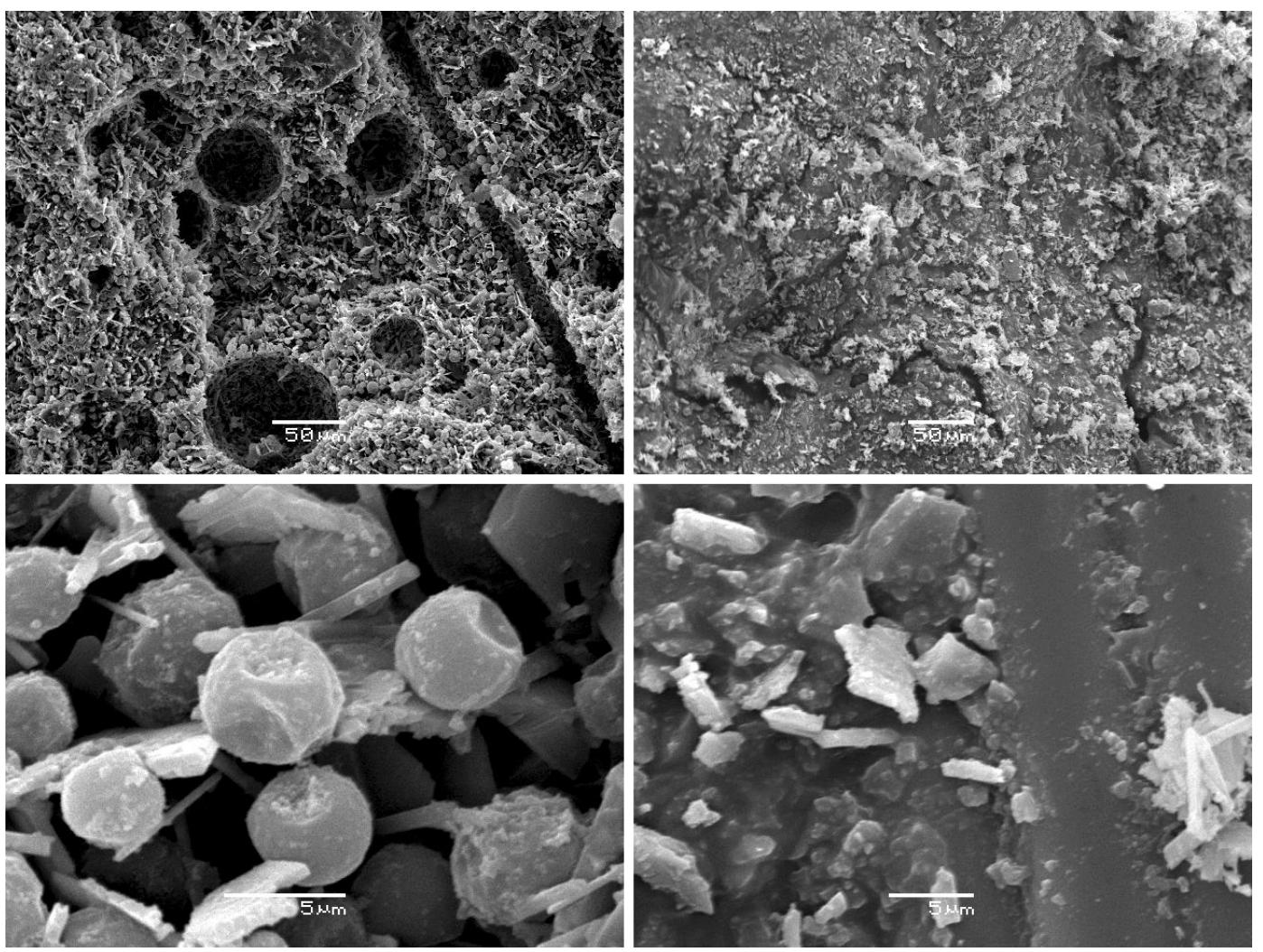

Figure 5. SEM images of GP+PCM samples before (left) and after (right) the $75 \mathrm{~kW} / \mathrm{m}^{2}$ cone calorimeter test. 


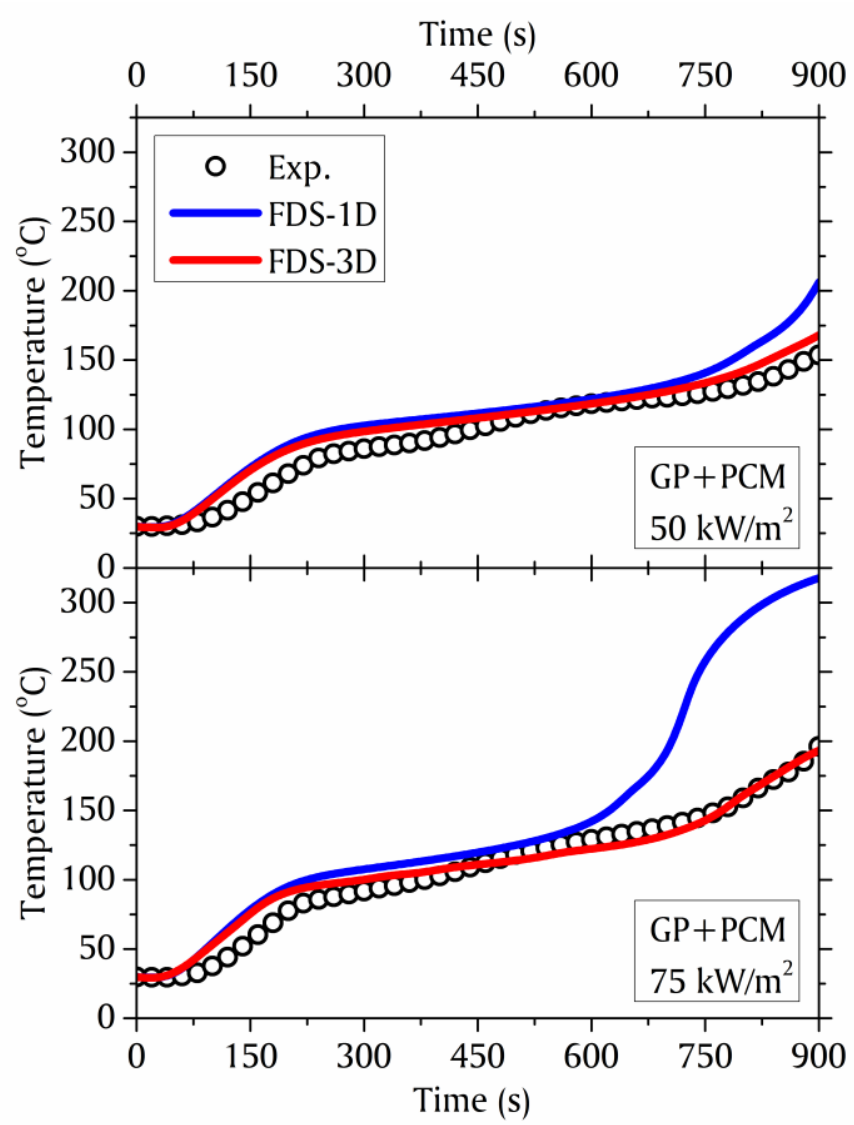

Figure 6. Measurements and CFD predictions of the bottom surface temperature of a $\mathrm{GP}+\mathrm{PCM}$ sample undergoing a cone calorimeter test, at an incident heat flux level of 50 $\mathrm{kW} / \mathrm{m}^{2}$ (top) and $75 \mathrm{~kW} / \mathrm{m}^{2}$ (bottom). 


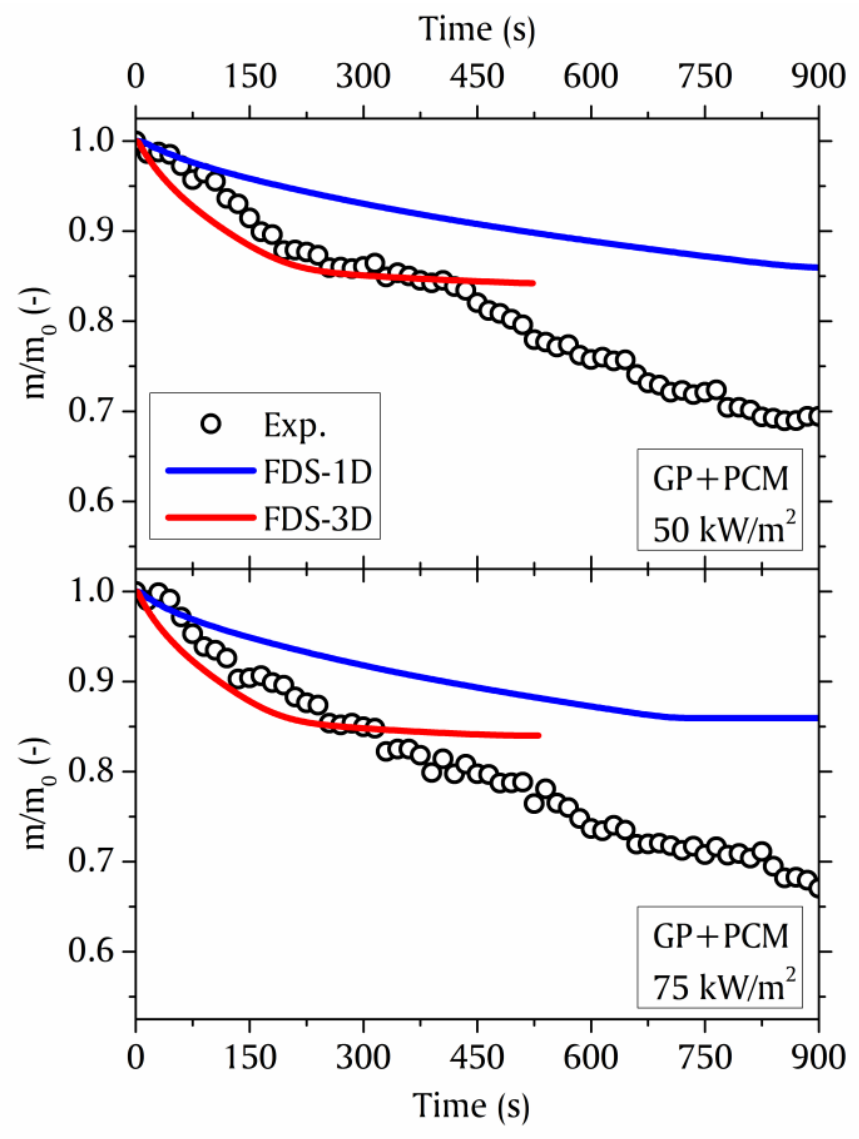

Figure 7. Measurements and CFD predictions of the instantaneous total mass of a GP+PCM sample undergoing a cone calorimeter test, at an incident heat flux level of $50 \mathrm{~kW} / \mathrm{m}^{2}$ (top) and $75 \mathrm{~kW} / \mathrm{m}^{2}$ (bottom).

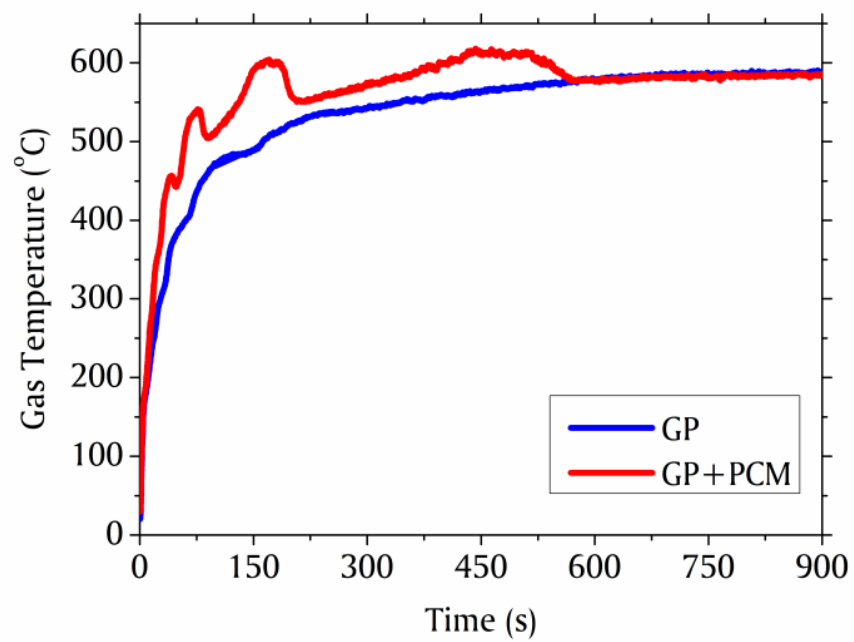

Figure 8. CFD predictions of the gas temperature immediately above the tested sample, for the GP and GP+PCM test cases. 


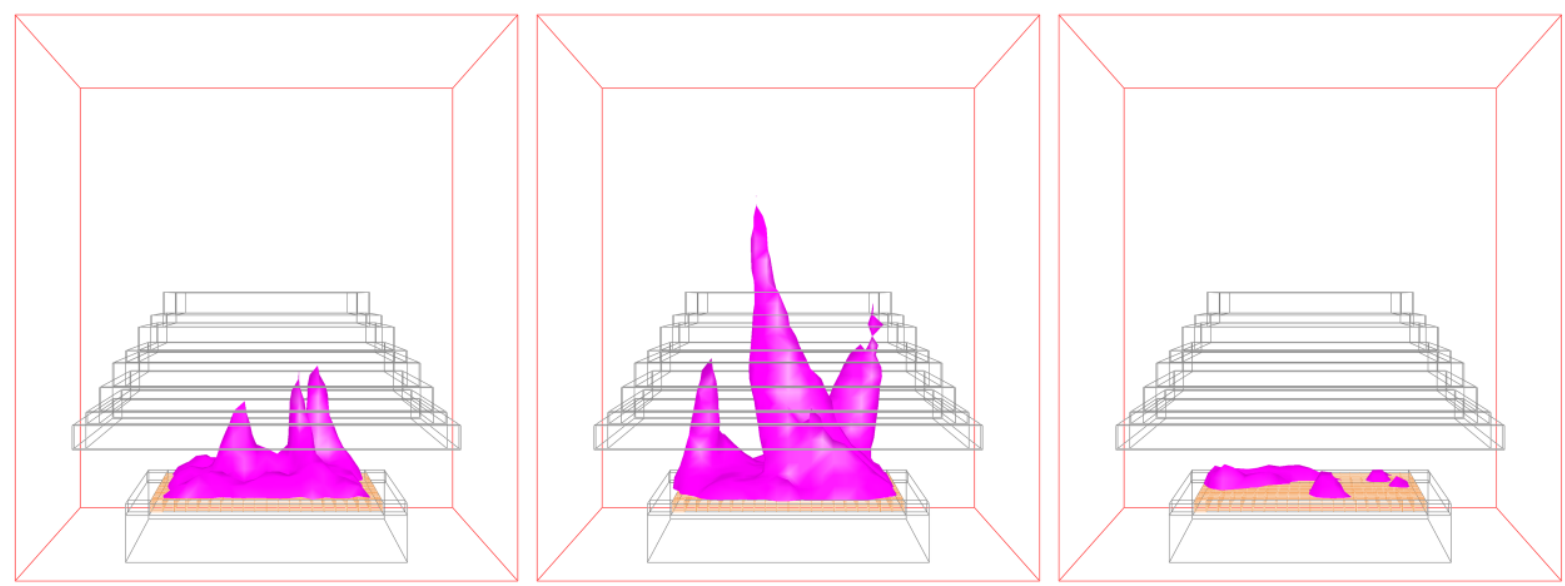

Figure 9. CFD predictions of $\mathrm{C}_{16} \mathrm{H}_{34}$ vapour $1 \%$ mass fraction iso-surface, $60 \mathrm{~s}$ (left), $180 \mathrm{~s}$ (middle) and $660 \mathrm{~s}$ (right) after initiation of the cone calorimeter test (GP+PCM). 